This item was submitted to Loughborough's Research Repository by the author.

Items in Figshare are protected by copyright, with all rights reserved, unless otherwise indicated.

\title{
Sustainable and self-regulating out-of-oven manufacturing of FRPs with integrated multifunctional capabilities
}

PLEASE CITE THE PUBLISHED VERSION

https://doi.org/10.1016/j.compscitech.2020.108032

\section{PUBLISHER}

Elsevier BV

VERSION

AM (Accepted Manuscript)

\section{PUBLISHER STATEMENT}

This paper was accepted for publication in the journal Composites Science and Technology and the definitive published version is available at https://doi.org/10.1016/j.compscitech.2020.108032.

LICENCE

CC BY-NC-ND 4.0

\section{REPOSITORY RECORD}

Liu, Yi, Tim van Vliet, Yinping Tao, James JC Busfield, Ton Peijs, Emiliano Bilotti, and Han Zhang. 2020. "Sustainable and Self-regulating Out-of-oven Manufacturing of Frps with Integrated Multifunctional Capabilities". Loughborough University. 


\title{
Sustainable and self-regulating out-of-oven manufacturing of FRPs with integrated multifunctional capabilities
}

\author{
Yi Liu, ${ }^{\mathrm{a}, \mathrm{b}}$ Tim van Vliet, ${ }^{\mathrm{c}}$ Yinping Tao, ${ }^{\mathrm{a}}$ James J.C. Busfield, ${ }^{\mathrm{a}}$ Ton Peijs, ${ }^{\mathrm{d}}$ Emiliano Bilotti, ${ }^{\mathrm{a}, \mathrm{b}}$ \\ Han Zhang a,b,*
}

a School of Engineering and Materials Science, Queen Mary University of London, Mile End Road, London E1 4NS, UK

${ }^{\mathrm{b}}$ Nanoforce Technology Ltd., Joseph Priestley Building, Queen Mary University of London, Mile End Road, E1 4NS London, UK

${ }^{c}$ Department of Mechanical Engineering, Eindhoven University of Technology, P.O. Box 513, 5600 MB Eindhoven, the Netherlands

${ }^{d}$ Materials Engineering Centre, WMG, University of Warwick, Coventry, CV4 7AL, UK

\begin{abstract}
With the ever increasing demand for energy reduction to stimulate sustainable development, new energy efficient manufacturing processes for advanced fibre-reinforced plastics (FRPs) are of great interest to overcome limitations of conventional autoclave or oven based manufacturing processes including high energy consumption and size restrictions. Herein, a highly energy efficient and safe out-of-oven curing method is presented by integrating a pyroresistive surface layer with intrinsic self-regulating heating capabilities, into a composite laminate. This surface layer consists of a nanocomposite film based on graphene nanoplatelets (GNPs) and high density polyethylene (HDPE) and possesses self-regulating Joule heating capabilities, which can be used to cure epoxy based composites at a desired temperature without the risk of over-heating. Moreover, the thermoplastic nature of the surface layer enables easy fabrication with good flexibility for complex shapes. Compared to state-of-the-art out-of-autoclave oven curing, the proposed out-of-oven Joule heating approach consumed only $1 \%$ of the energy required for


curing, with no effect on mechanical performance and glass transition temperature $\left(\mathrm{T}_{\mathrm{g}}\right)$ of the final composite. Moreover, the integration of the self-regulating heating layer offers additional functionalities to the cured composites, like strain or damage sensing as well as the potential of de-icing without affecting the internal structure and performance of the laminate. The presented smart heating layer provides a novel solution for sustainable manufacturing as well as real-time structural health monitoring (SHM) throughout the components' life for multifunctional composite applications in the field of renewable wind energy and aerospace.

Keywords: Composites, Sustainable manufacturing, Out-of-oven curing, Joule heating, Positive temperature coefficient (PTC) effect, Sensing, De-icing.

\section{Introduction}

Fibre reinforced plastics (FRPs) are replacing traditional metallic materials in various industries, especially in lightweight and energy efficient structural applications such as aerospace and automotive, due to their appealing properties of high specific strength and stiffness [1]. Traditionally, structural thermoset based FRPs as used, for example, in the aircraft industry are produced using autoclave technologies which are extremely energy and capital intensive. Therefore, more energy and cost effective manufacturing methods such as vacuum assisted resin transfer moulding (VARTM) and vacuum assisted resin infusion (VARI) often in combination with oven curing have been developed over the last few decades [2, 3]. These technologies have received wide acceptance due to their increasingly high quality and reproducibility together with significantly lower energy consumption and capital/running costs. However, due to the nature of both autoclave and oven heating, a vast amount of energy is consumed to heat up the air in the autoclave or oven first, before it is used to cure the composite part surrounded by the elevated environmental temperature, limiting their energy conversion efficiency. It is also worth noting 
that the capacity of autoclave or oven clearly limits the size and therefore the design of components, introducing the necessity of joining and assembling which is not always desirable with respect to product quality, durability as well as manufacturing costs. Clearly, considering the ever increasing demand for structural FRP components with the rapid developments in future civil aircraft, electric vehicles, and off-shore wind energy, novel innovative ways to manufacture composite parts are of great interest. Such methods need to fulfil requirements of energy efficiency and sustainable manufacturing, curing and process control, and the potential of manufacturing large and complex parts. Moreover, in certain areas such as large wind turbine blades there is a drive to manufacture parts near the erection site to avoid complications and environmental impact due to transportation, as well as to perform onsite repair upon damage.

The recent interest in nanomaterials, especially carbon based nanofillers like carbon nanotubes (CNTs) and graphene nanoplatelets (GNPs) with good thermal and electrical properties have enabled the development of many high performance multifunctional composites [4-8]. The use of CNTs and/or GNPs has not only introduced multifunctionalities like electrical or thermal conductivities and strain or damage sensing capabilities [9-13], but has also demonstrated its potential as a Joule heating source to efficiently heat up composite laminates and cure thermoset resins [14-19]. For example, Lee et al. reported an out-of-oven curing technique via resistive heating of an aligned carbon nanotube film, which could be detached after curing. The energy consumption was reported to be over two orders of magnitude lower (14 vs. $0.1 \mathrm{MJ})$ as compared to the oven cure baseline [20]. Xu et al. fabricated a large scale CNT film as heating source to perform the in-situ curing of glass fibre reinforced plastics (GFRPs), leading to outstanding uniformity in thickness, surface resistance and temperature, using only one seventh of the energy consumption of the oven curing process [21]. Vertuccio et al. designed a flexible graphene film to be placed between two carbon fibre reinforced plastic (CFRP) laminates, which required up to nine times less power, while at the same time providing de-icing capabilities [14]. Clearly, 
self-heating or electro-heating using CNT or other carbon nanomaterial based nanocomposite films could be a promising alternative for current oven or autoclave based composite manufacturing methods, with great energy saving potential, especially for large components [2225].

However, despite their potential, the excellent heating capabilities and thermal conductivities of conductive nanocomposite films also raise some serious safety concerns for Joule heating based applications like the possibility of overheating and burning. The heating rate can be extremely high in the case of for example CNT film heaters, resulting in strong exothermic reactions and the potential of overheating hence causing damage and/or burning of components and workplace. In order to be considered by industry, the above mentioned out-of-oven methods need a wellcontrolled external current to maintain the curing temperature within limits, meaning that the current needs to be adjusted throughout the curing process, adding extra complexity with potential safety hazards. To solve this issue and open up the potential of this evolving field, a conductive nanocomposite heating layer with intrinsic self-regulating heating capabilities would greatly improve the use and safety of the Joule heating method for curing thermoset composites.

A well designed conductive polymer composites (CPC) exhibiting a positive temperature coefficient (PTC) effect should be a great candidate to fulfil both efficient Joule heating capabilities as well as introduce high safety standards without the need of an external current controller $[26,27]$. The PTC effect is generally believed to be associate with a mismatch of thermal expansion coefficient between polymeric matrix and conductive fillers, particularly evident in correspondence with a phase transition (e.g. melting) of a semi-crystalline polymer matrix. This is due to the significant volume expansion of such a polymer matrix at the transition temperature, resulting in a sudden increase in inter-particle distance between the conductive fillers. Conversely, when the composite cools, the polymer matrix shrinks and the average interparticle distance decreases, reforming conductive pathways in the matrix and restoring electrical 
conductivity [28]. This PTC effect leads to an autonomous heating cut-off and re-establishment of conductivity and heating when reaching a pre-designed safety temperature, hence providing a safe self-regulating heating effect without the need of an external control system [28-30].

In this work, a conductive nanocomposite heating film with intrinsic self-regulating heating capabilities is fabricated and utilised to perform out-of-oven curing of GFPRs. The heating layer or film consisting of GNPs and high density polyethylene (HDPE) possesses an excellent PTC effect due to the outstanding Joule heating and thermal properties of GNPs in combination with the high thermal expansion rate of the HDPE matrix [28, 31-35]. The curing process was performed via Joule (resistive) heating of an embedded HDPE/GNP surface film on glass fibre preforms at a desired temperature, with direct connection to a power source. No external temperature controller was needed as the developed pyroresistive heating layer heats up homogeneously and autonomously regulates the curing temperature at the desire level. Unlike traditional heating devices such as heating blankets, the conductive nanocomposite layer can be integrated into the surface of the composite laminate after curing, opening up the possibility to use it as a smart surface layer which introduces various multifunctional properties into composite components ranging from strain and damage sensing to Joule heating for de-icing or colour change.

\section{Experimental}

\subsection{Materials}

High density polyethylene (HDPE) from INEOS (HD5218EA) and graphene nanoplatelets (GNPs) from XG Science (Grade M15) were used as received to fabricate the self-regulating nanocomposite layer. The composite system consisted of non-crimp cross-ply glass fibre fabrics (FORMAX, fibre type E-Glass TD22) with an aerial weight of $311 \mathrm{~g} / \mathrm{m}^{2}$ as reinforcement, and 
a low viscosity RX771C (bisphenol A diglycidyl ether, DGEBA) and HX932C (aromatic amine) were supplied from Robnor Resinlab ${ }^{\circledR}$, with an optimum cure cycle of $120^{\circ} \mathrm{C}$ for $12 \mathrm{hrs}$ [36]. HDPE is chosen due to its PTC switching temperature of $120^{\circ} \mathrm{C}$ to match the required curing temperature for current resin system. Thermochromic paint used in this work was from SFXC ${ }^{\circledR}$, with a transition temperature at $47^{\circ} \mathrm{C}$. It is also worth noting that for other resin systems with different curing temperatures, different semi-crystalline polymers with PTC switching temperature matching required profiles should be used.

\subsection{Fabrication of composites}

A Collin twin-screw extruder $(Z K 25,25 \mathrm{~mm}, \mathrm{~L} / \mathrm{D}=40)$ was used to produce the self-regulating HDPE/GNP composite with a GNP loading of $24 \mathrm{wt} . \%$. Extruder throughput was $2 \mathrm{~kg} / \mathrm{h}$ using a screw speed of $220 \mathrm{rpm}$ and a temperature profile ranging from $190{ }^{\circ} \mathrm{C}$ to $240{ }^{\circ} \mathrm{C}$, over 8 heating zones [7]. The pelletized HDPE/GNP compound was then compression moulded using a Collin P300E hot press into films (150 to $200 \mu \mathrm{m}$ thick) at a temperature of $200{ }^{\circ} \mathrm{C}$ for $10 \mathrm{~min}$.

Thin copper wires were used as electrodes for the nanocomposite film while contact resistance between embedded wires and surrounding film was negligible. The wires, spaced $15 \mathrm{~mm}$ apart, were sandwiched between two HDPE/GNP layers and compression moulded to a final film with a thickness of about $250 \mu \mathrm{m}$ (Fig. 1a). The spaced electrodes were then connected to a copper strip attached to both sides of the composite film. The average dimensions of the fabricated films were $140 \mathrm{~mm} \times 100 \mathrm{~mm} \times 0.25 \mathrm{~mm}$.

The fabricated PTC film was then used as the heating source to cure a glass fibre reinforced plastic (GFRP) laminate. For this the PTC nanocomposite heating film was placed on top of cross-ply glass fibre fabrics (12 layers with a lay-up of [0/90/90/0/0/90 $]_{\mathrm{s}}$ ) as illustrated in Fig. 1b. Three thermocouples were employed to record the temperature of the composite laminate at 
different locations throughout the cure cycle (Fig. 1c) [37]. The vacuum assisted resin infusion (VARI) method to manufacture the GFRP laminate is schematically illustrated in Fig. 1d.

In order to have a direct comparison with a conventional oven curing process, the latter was also employed to cure a composite laminate with the same layup and surface layer after the resin infusion procedure, alongside the laminate cured via the Joule heating method by the embedded HDPE/GNP nanocomposite surface layer. It is worth noting that in order to improve the adhesion between the nanocomposite surface film and the GFRP laminate, the films were corona treated for 30 seconds prior to resin infusion. After curing, panels with dimensions of $120 \mathrm{~mm} \times 100$ $\mathrm{mm} \times 1.8 \mathrm{~mm}$ were obtained for subsequent characterisation.

(a)

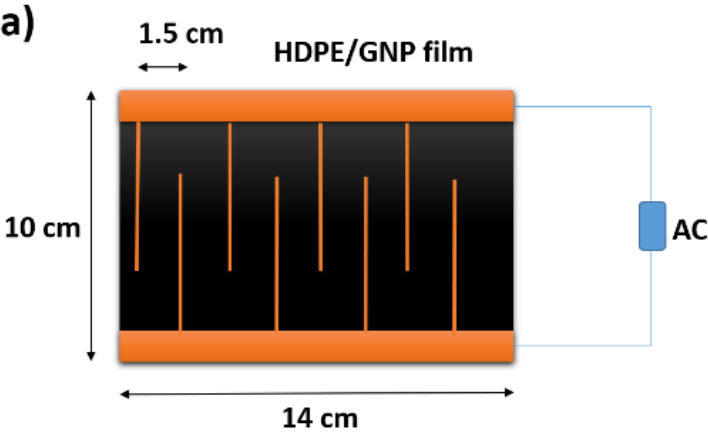

(c)

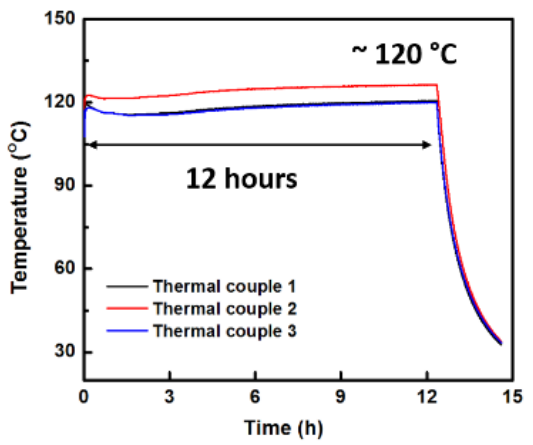

(b)

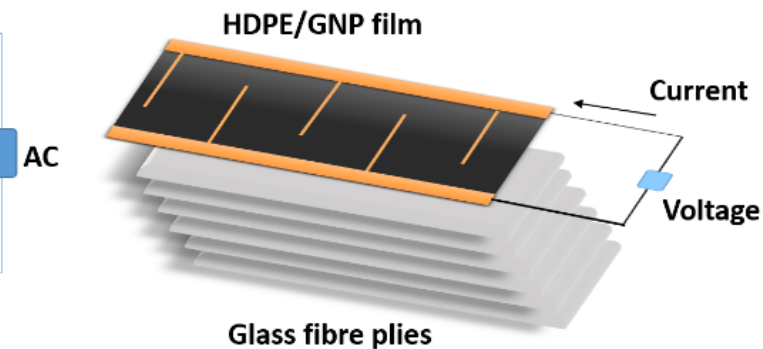

(d)

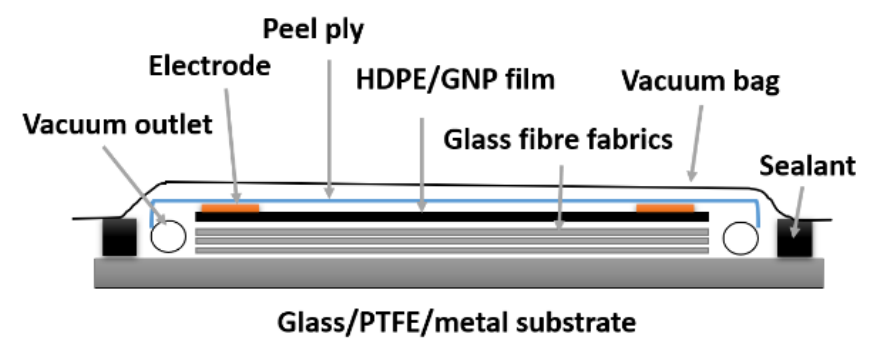

Figure 1. (a) Illustration and image of the fabricated HDPE/GNP film with electrodes, with dimensions of $140 \mathrm{~mm} \times 100 \mathrm{~mm} \times 0.25 \mathrm{~mm}$; (b) layup with HDPE/GNP film on top of glass fibre fabrics; (c) curing profile of epoxy based GFRP; (d) schematic of VARI process. 


\subsection{Characterisations}

\subsubsection{Scanning electron microscopy (SEM)}

Scanning electron microscopy (SEM) (FEI Inspector-F) was used to examine the morphology of the cured composite laminates. Cryo-fractured surfaces of HDPE/GNP films were induced by immersing the specimens into liquid nitrogen for $10 \mathrm{~min}$ prior to fracturing. All surfaces examined were gold sputtered before imaging.

\subsubsection{Thermal testing and power consumption}

The temperature profile of the samples during the curing process was recorded by a Thermocouple Data Logger (Pico Technology TC-08) with three thermocouples attached to both ends and the middle of the mould, as illustrated in Fig. 2. An AC power supply (GE EPS 301) was used to apply a voltage to the nanocomposite film, with the current monitored simultaneously as shown in Fig. 2a. The power consumption of the Joule heating based curing method is calculated by multiplying the voltage and current values, while the power consumption during curing in traditional convection ovens (Thermo Scientific, Heratherm OMH750 and OMH180-S) were monitored and recorded directly by a plug-in power monitor (Model 2000MUUK), as illustrated in Fig. 2b. The heating capabilities of the self-regulating nanocomposite film were examined both before and after curing using a thermal infrared (IR) camera (FLIR A35). 
(a) Out-of-Oven

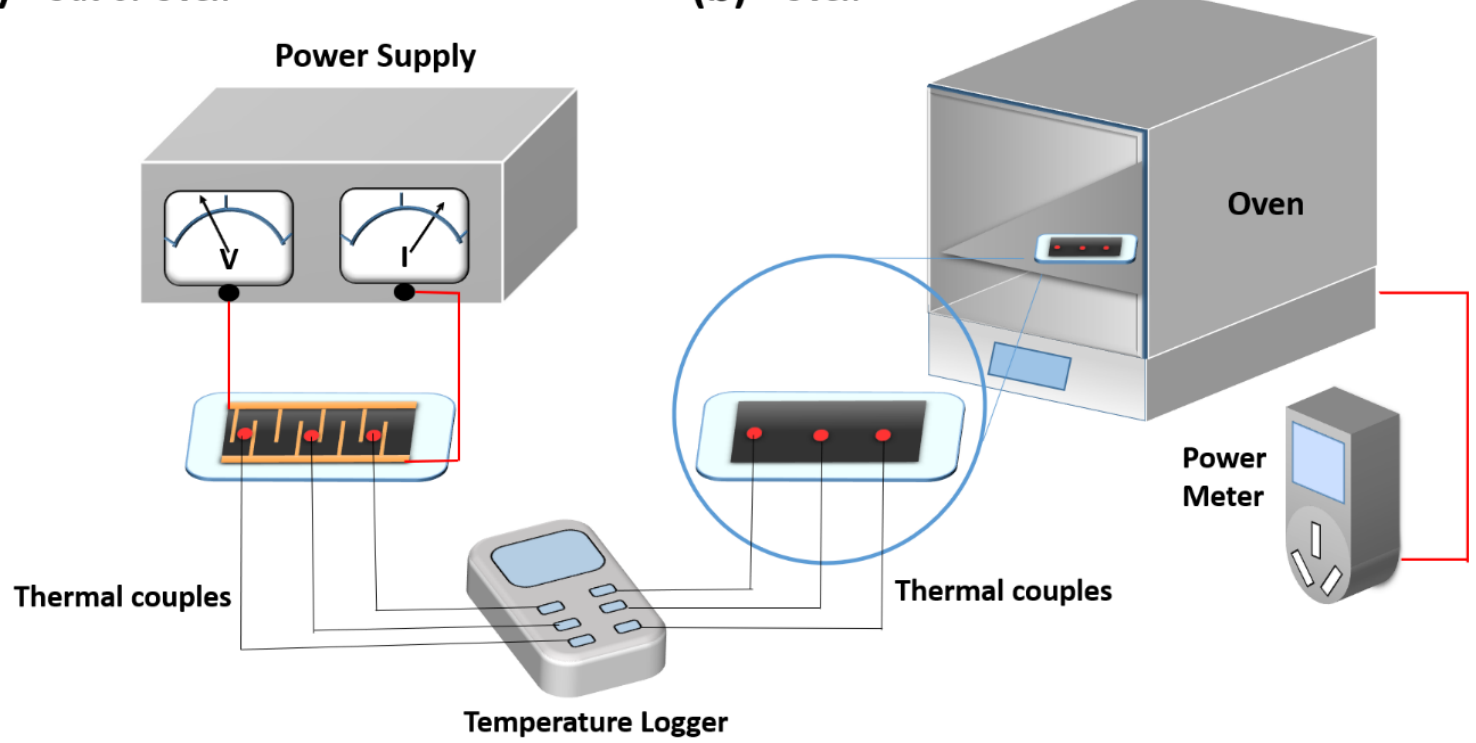

Figure 2. Illustrations of: (a) the power supply which was setup to apply a set voltage to the sample with temperature and current recorded simultaneously; (b) the power consumption of the oven during curing was monitored by a plug-in power meter while the temperature profile was recorded by a temperature logger through three thermocouples attached to the laminates.

2.3.3 Mechanical properties and dynamic mechanical analysis (DMA)

Three-point bending tests were performed to examine the influence of the Joule heating based curing method on the mechanical properties of the GFRP laminates. Flexural properties for both sets of laminates were assessed in accordance with ASTM standard D790 using an Instron 5586 with $100 \mathrm{~N}$ load cell at room temperature (RT), at a strain rate of $1 \% / \mathrm{min}$. DMA was performed on the GFRP laminates using a TA Instruments DMA Q800 equipped with a fixture for three point bending. The temperature scans from $30{ }^{\circ} \mathrm{C}$ to $150{ }^{\circ} \mathrm{C}$ at the rate of $3{ }^{\circ} \mathrm{C} / \mathrm{min}$ have been applied to characterise the $\mathrm{Tg}$, while the storage modulus were measured at $30{ }^{\circ} \mathrm{C}$ for all specimens. A frequency of $1 \mathrm{~Hz}$ and strain of $1 \%$ were chosen for the tests. Five samples were tested to obtain an average value.

2.3.4 Strain and damage sensing 
The strain and damage sensing capabilities of the multifunctional film were examined based on an electrical method, with an in-situ two-point electrical resistance measurement setup consisting of a multimeter (Agilent 34401A) connected to a data acquisition system to simultaneously record the load and displacement from the Instron machine. Five samples have been tested. Cyclic loadings with the maximum strain of $0.1 \%$ and $0.2 \%$ respectively were applied at the strain rate of $1 \% / \mathrm{min}$, separated by a relaxation period of one minute in between.

\section{Results and discussion}

\subsection{Self-regulating Joule heating of HDPE/GNP nanocomposite film}

For any heating application, an efficient Joule heating performance is an essential requirement. On the other hand, to satisfy a high safety standard based on self-regulation, a positive temperature coefficient (PTC) effect with a clear electrical resistance jump at the desired cure temperature is a necessity to cut off the current in order to avoid overheating. Therefore, prior to integrating the fabricated conductive nanocomposite film into the composite laminate, its selfregulating Joule heating performance was examined and analysed.

The temperature and electrical resistance change of the HDPE/GNP film under applied voltage $(50 \mathrm{~V})$ were recorded and presented in Fig. 3. A voltage of $50 \mathrm{~V}$ is chosen for an efficient heating performance, with temperature raising from RT to more than $100{ }^{\circ} \mathrm{C}$ within 10 min (Fig. 3a), indicating a good heating capability. With higher voltage applied, a higher heating efficiency can be expected, while the final temperature is self-regulated at the same level. With temperatures approaching $120^{\circ} \mathrm{C}$, the heating rate is autonomously reduced and temperature is stabilised at $120{ }^{\circ} \mathrm{C}$ after $20 \mathrm{~min}$. Similar to any heating device, a dramatic drop in power consumption was observed during heating with an autonomous decrease in values, from the 
highest power consumption at RT when maximum heating is required, to a minimum consumption at $120^{\circ} \mathrm{C}$ when only limited power is required to maintain this temperature.

The effect of temperature on the electrical resistance of the HDPE/GNP film is shown in Fig. $3 b$. The resistance of the nanocomposite film barely changed from $\mathrm{RT}$ until $110^{\circ} \mathrm{C}$, followed by a very sharp increase when approaching $120^{\circ} \mathrm{C}$, indicating a clear and large PTC effect. This sharp increase in resistance is attributed to the intrinsic PTC effect of the HDPE/GNP film, originating from the mismatch in thermal expansion coefficient between HDPE matrix and conductive GNP fillers. Thermal expansion of the HDPE matrix resulted in disruption of the percolated GNP network, when the temperature approaches $120{ }^{\circ} \mathrm{C}$ (close to the melting temperature $\left(\mathrm{T}_{\mathrm{m}}\right)$ of HDPE), leading to increased electrical resistance and hence reduced heating [38]. Conversely, when temperature drops, the GNP conductive network is reformed upon shrinkage of the polymer matrix and Joule heating restarts. Clearly, for the current epoxy based GFRP system where a $120^{\circ} \mathrm{C}$ curing temperature is required, the HDPE/GNP nanocomposite film can perform the heating without any external current controller since the temperature is self-maintained at $120{ }^{\circ} \mathrm{C}$ and never exceeded this temperature. By changing the semi-crystalline polymers, the PTC temperatures also can be tailored in accordance to required curing profiles. It is also worth noting that due to the excellent thermal conductivity of graphene nanofillers, a reasonably homogeneous heating distribution can be obtained in the nanocomposite film (Fig. 3b inset), providing a consistent and homogenous heating of the GFRP laminate throughout curing. 
(a)

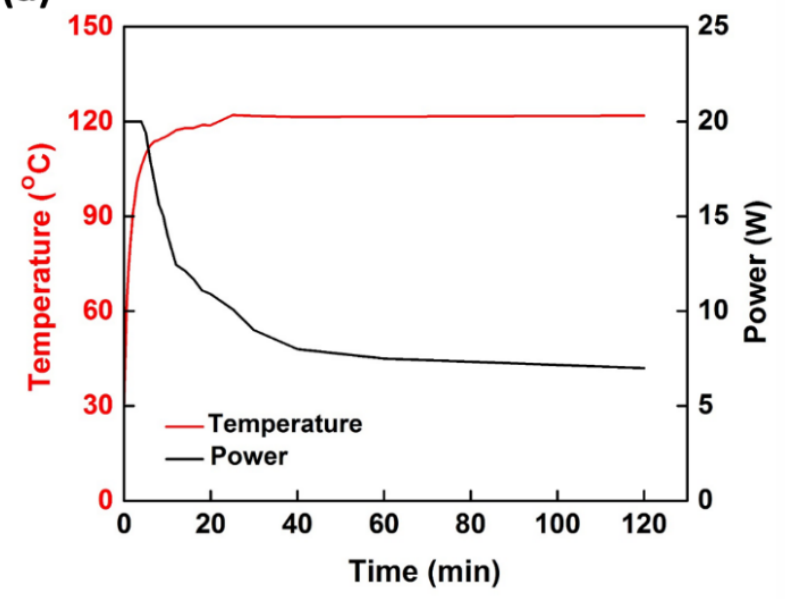

(b)

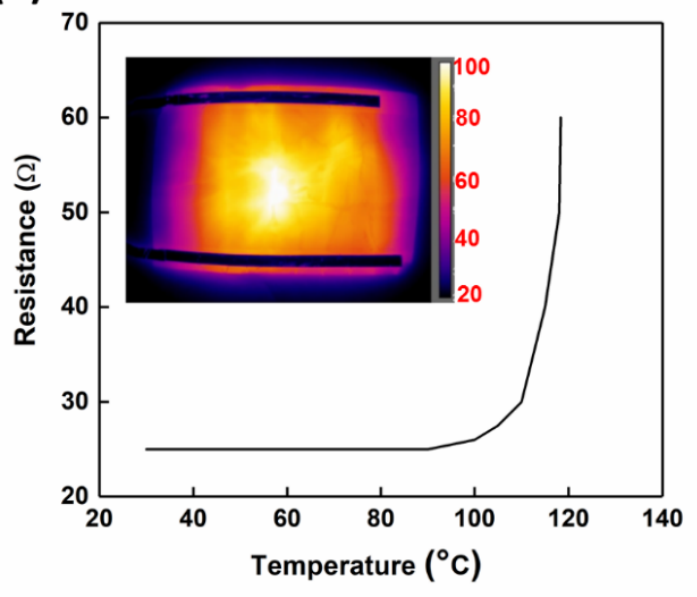

Figure 3. (a) A stable self-regulating heating temperature around $120^{\circ} \mathrm{C}$ is achieved within 10 min using the HDPE/GNP film, with a sharp and autonomous decrease in heating power; (b) resistance change of the nanocomposite film with elevated temperature, with a clear resistance jump when temperature approaches $120^{\circ} \mathrm{C}$, confirming a clear and large PTC effect. (Inset: thermal IR image showing the temperature distribution in degree Celsius throughout the HDPE/GNP film.)

\subsection{Morphologies}

Apart from the intrinsic self-regulating heating capabilities of the HDPE/GNP nanocomposite film, another innovative design of the current multifunctional system is to embed the nanocomposite film into the surface of the GFRP laminate, hence fully integrating this "heating layer" as part of the final composite structure after curing but without affecting its internal structural integrity. Therefore, the morphology of each of the constituents as well as the cured composite laminate have been examined. The liquid nitrogen cryo-fractured surface of the HDPE/GNP film is presented in Fig. 4a, showing a clear trace of GNPs dispersed within the HDPE matrix. Considering the high loading of GNPs (24 wt.\%), the dispersion level is relatively homogeneous without large agglomerates. GNPs are preferentially oriented in-plane, which is believed to be due to the flow in the compression moulding process during film fabrication. Fig. 
$4 \mathrm{~b}$ shows the cross-sectional view of the cured composite laminates with the $\mathrm{CPC}$ layer firmly attached to one side of the GFRP laminate. A close view of the GFRP laminate at higher magnification is shown in Fig. 4c, showing glass fibres closely packed with no obvious voids present in the laminate.

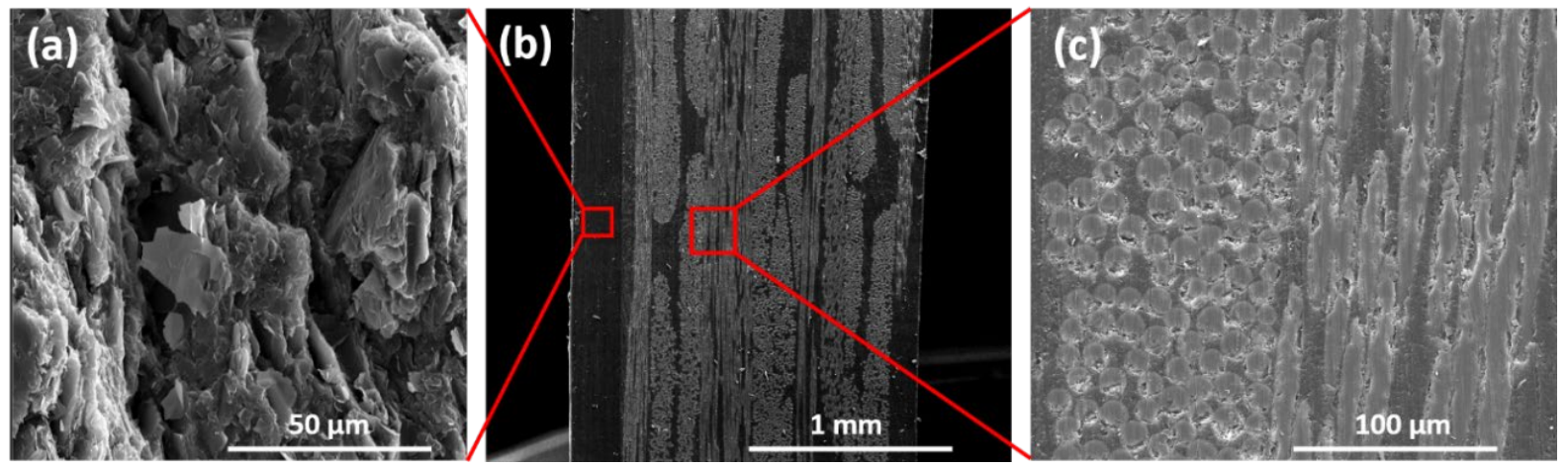

Figure 4. Morphology of (a) cryo-fractured HDPE/GNP nanocomposite film; (b) nanocomposite film firmly attached to the GFRP laminate; (c) higher magnification of GFRP laminate showing internal structure of the laminate.

\subsection{Self-regulating out-of-oven versus traditional oven curing}

In order to have a clear comparison between the out-of-oven self-regulating Joule heating and traditional oven heating curing, the power consumption, temperature profile, glass transition temperature $\left(\mathrm{T}_{\mathrm{g}}\right)$ as well as mechanical properties of the cured laminates have been characterised and compared for both manufacturing methods.

Fig. 5a presents the temperature profiles for both the Joule heating and oven curing. The temperature of the oven heating process (black line) shows a linear slope at the beginning of process, which corresponds to the set heating rate of $3{ }^{\circ} \mathrm{C} / \mathrm{min}$, followed by an isothermal curing stage at $120^{\circ} \mathrm{C}$ for $12 \mathrm{hrs}$. The relatively slow cooling process of the oven based method after $12 \mathrm{hrs}$ is attributed to the direct switch-off of the oven without continued fan assisted temperature ramping. The Joule heating method (red line) shows a similar overall temperature profile to the oven curing method, with the equilibrium temperature $\left(120^{\circ} \mathrm{C}\right)$ reached at a much faster ramp 
rate due to the excellent Joule heating capabilities of the nanocomposite layer. Although the same direct power cut-off after 12 hrs of curing was applied, a more efficient autonomous cooling process was also observed for the Joule heating method since the heated area and volume is much smaller than the internal capacity of the oven.

Fig. $5 \mathrm{~b}$ shows the power consumption of both manufacturing processes during the $12 \mathrm{hrs}$ curing cycle. In order to compare the energy consumption of ovens of different size, the power of a large 730 litre oven (black line) and smaller 170 litre oven (blue line) for the same curing procedure were measured and shown in Figure 5b. A distinct difference in the starting point of power consumption can be found between the oven and the Joule heating process, with over $2500 \mathrm{~W}$ power consumed for the oven based manufacturing process compared to only $20 \mathrm{~W}$ for the Joule heating based method. This is mainly due to the differences in heating mechanisms as well as differences in the volumes of materials and air required to be heated up. Convectional ovens need to heat up the air within the oven first before heating up the mould and composite panel, while Joule heating directly generates heat within the nanocomposite film which is in direct contact with the composite layup via a more efficient conduction heating mechanism, without the need of converting electricity into large quantities of hot air.

As mentioned earlier, power consumption for most heating applications is at its highest when heating is initiated, then gradually reduced and stabilised to a lower level of power consumption when the temperature reaches its equilibrium. Therefore, similar reducing trends of power consumption can be found for both methods, although the equilibrium level for Joule heating ( $5 \mathrm{~W})$ was two orders of magnitudes lower than for oven based heating $(\sim 500 \mathrm{~W})$. 
(a)

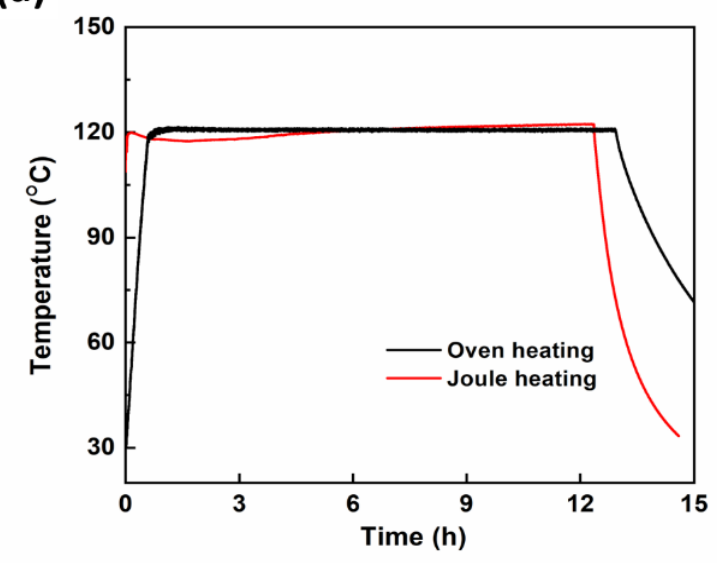

(b)

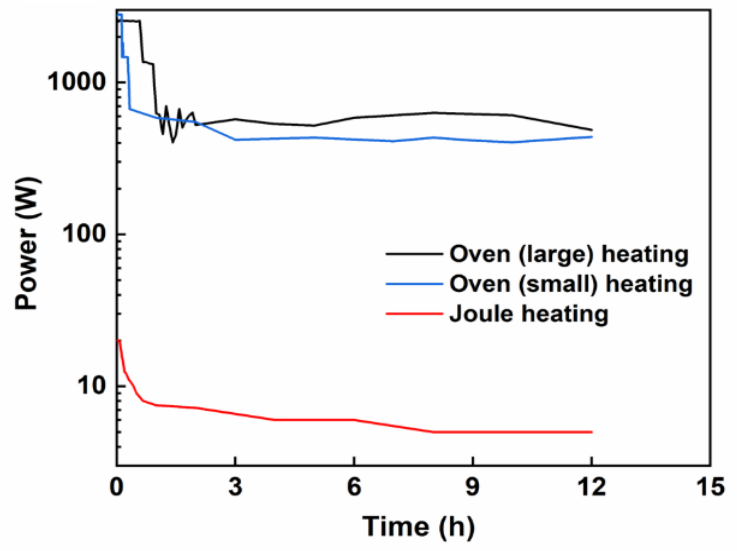

Figure 5. Direct comparisons between oven (black lines) and Joule heating (red lines) based curing processes: (a) temperature profiles of the two methods for a complete curing process; (b) power consumption value of the two methods. The Joule heating method shows an enormous reduction in power consumption by two orders of magnitude compared to two oven heating (both large 730 litre and small 170 litre).

It is worth noting that since the dimensions of the Joule heating film can be adjusted and tailored to fit the surface dimensions of the composite laminate, the energy savings in the case of large components are expected to be even higher. This is due to the necessity of using an autoclave or oven that scales in size with the component, meaning that the difference in heated volumes between part and oven or autoclave becomes increasingly larger. Although in the current demonstration of curing using the self-regulating Joule heating film the gradient between upper and lower surface temperature of the laminate was negligible, there could be a concern of its feasibility in case of thick laminates. Therefore, a theoretical estimation based on thermal conduction theory was performed to assess its potential for thick laminates. For this the basic (1D) steady-state heat flow equation was used as shown in Eq. 1 [39].

$$
q=-K \frac{\partial T}{\partial x}
$$


Where $q$ is the heat flux $\left(\mathrm{W} \cdot \mathrm{m}^{-2}\right), \partial T / \partial x\left(\mathrm{~K} \cdot \mathrm{m}^{-1}\right)$ is the thermal gradient, $K$ is thermal conductivity of a material $\left(\mathrm{W} \cdot \mathrm{m}^{-1} \cdot \mathrm{K}^{-1}\right)$.

Using a fixed temperature gradient from top (heating layer) to bottom (tool side) of the laminate, and a pre-set acceptable curing temperature gradient of $3{ }^{\circ} \mathrm{C}$ under equilibrium condition, the current method should be able to cure GFRP laminates up to $16 \mathrm{~mm}$. Therefore, it is believed that with current Joule heating method, composite panels with thicknesses up to a few $\mathrm{mm}$ can be cured homogeneously. Considering that the heat transfer mechanism within the composite laminate is the same for both oven and current Joule heating method, i.e. both relying on heat transfer from the laminate surface to the inside of laminate, the current method should be able to cure thick panel as well.

The total energy consumptions during the entire curing cycles was about $7 \mathrm{kWh}$ for the larger oven $(730 \mathrm{~L})$ and $5.7 \mathrm{kWh}$ for the smaller oven (180L) while only $0.075 \mathrm{kWh}$ for the Joule heated system. Although the smaller oven draws slightly less power $(5.7 \mathrm{kWh})$ compare to larger oven $(7 \mathrm{kWh})$, both energy consumption levels are at the same order of magnitude regardless of their size difference. Clearly, the Joule heating curing method is a significantly more energy efficient manufacturing method for curing composite laminates, with only $1 \%$ of electrical energy needed to cure the same laminate. Since oven heating has already a significantly reduced $(80 \%)$ energy consumption profile compared to autoclave curing [40], the proposed Joule heating method using nanocomposite films with intrinsic self-regulating properties provides here an even larger benefit in terms of energy consumption.

The mechanical performance of the cured GFRP laminates is examined for the Joule heating based out-of-oven process as well as the oven cured laminates, since structural integrity and performance should not be sacrificed for lower energy consumption during manufacturing. Fig. 6a shows the flexural modulus and strength of the GFRP laminates manufactured by both Joule 
heating and oven heating methods. No obvious difference can be observed in their elastic modulus and flexural strength values, indicating that the mechanical performance which is closely linked to the degree of cure of epoxy are similar for both methods. This observation is not surprising since the temperature profiles of two methods are very similar as discussed earlier, leading to a similar degree of cross-linking at the end of process. This has also been confirmed by the similar level of glass transition temperatures $\left(\mathrm{T}_{\mathrm{g}}\right)$ as well as comparable storage modulus values at $30{ }^{\circ} \mathrm{C}$ without obvious difference between the two methods (Fig. 6b), although the measured modulus values for the out-of-oven method were slightly higher than for the traditional curing method. Therefore, it is believed that the current Joule heating method using an embedded nanocomposite film into the GFRP laminate is an efficient alternative to traditional oven curing, while the integrated control of the curing temperature adds quality assurance and consistency in mechanical performance of cured components.

(a)

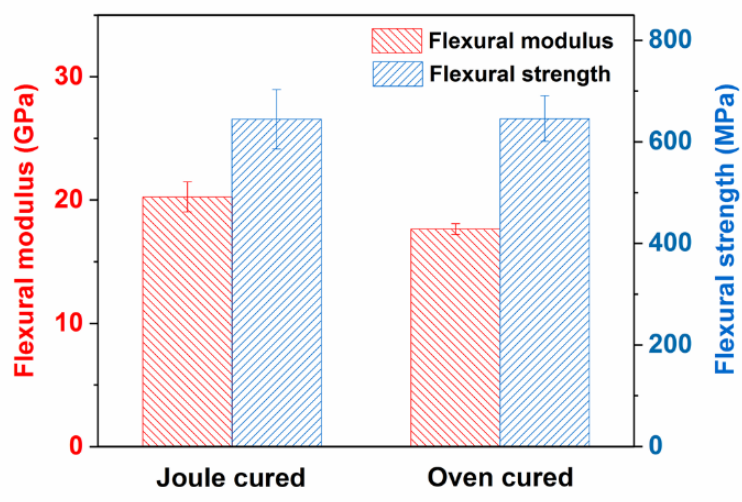

(b)

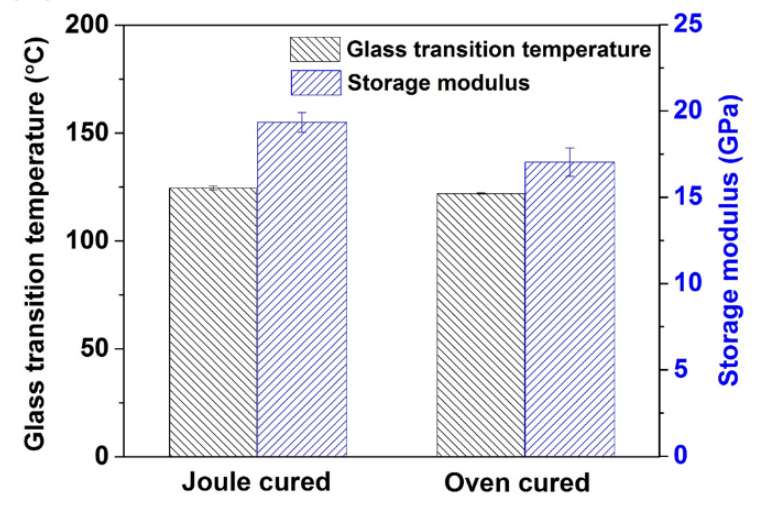

Figure 6. Comparison of composite properties by both Joule cured and oven cured GFRP samples, showing no obvious difference between the two curing methods. a) Flexural modulus and flexural strength; b) $T_{g}$ and storage modulus. Atmospheric pressure was applied through the applied vacuum bag which was the same for both methods; the temperature profiles were very similar as presented earlier, hence no obvious differences in mechanical properties should be anticipated. 


\subsection{De-icing capability of HDPE/GNP nanocomposite film}

As demonstrated earlier, the self-regulating HDPE/GNP nanocomposite film can be used as an efficient Joule heating layer to cure thermoset based laminates. The same heating capabilities can also be utilised subsequently to perform the de-icing function during the usage of the composite laminate or structure. The de-icing capability of the fabricated GFRP laminates was successfully demonstrated using the integrated Joule heating nanocomposite layer at different environment temperatures, for instance at $-20^{\circ} \mathrm{C}$ as shown in Fig. 7a.

Clearly, the embedded nanocomposite film is robust enough to not only 'perform and survive' the curing process, but also acts as an active surface layer which can heat up the composite laminate from different ambient temperatures, including sub-zero temperatures. Efficient heating was obtained in the composite laminates, requiring only $100 \mathrm{~s}$ to reach $20{ }^{\circ} \mathrm{C}$ from $-10{ }^{\circ} \mathrm{C}$ (heating rate $18^{\circ} \mathrm{C} / \mathrm{min}$ ). Fig. $7 \mathrm{~b}$ shows a thermal image of the GFRP laminate, confirming the homogeneous heat distribution throughout the surface area of the panel. In addition, the current Joule heating capability in combination with thermochromic paints can be used for colour changing effects with potential applications in camouflage as shown in Fig. 7c. 
(a)

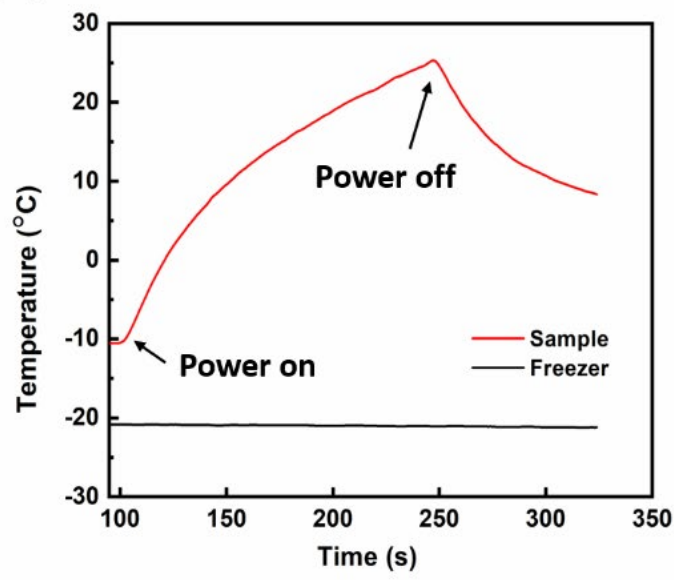

(b)

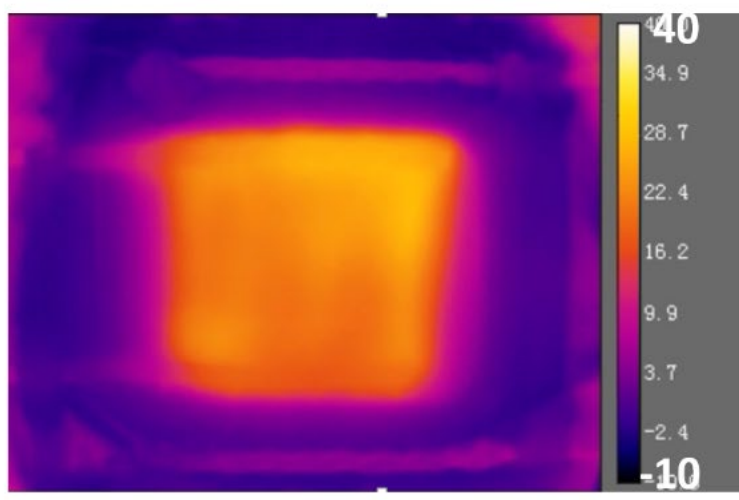

(c)
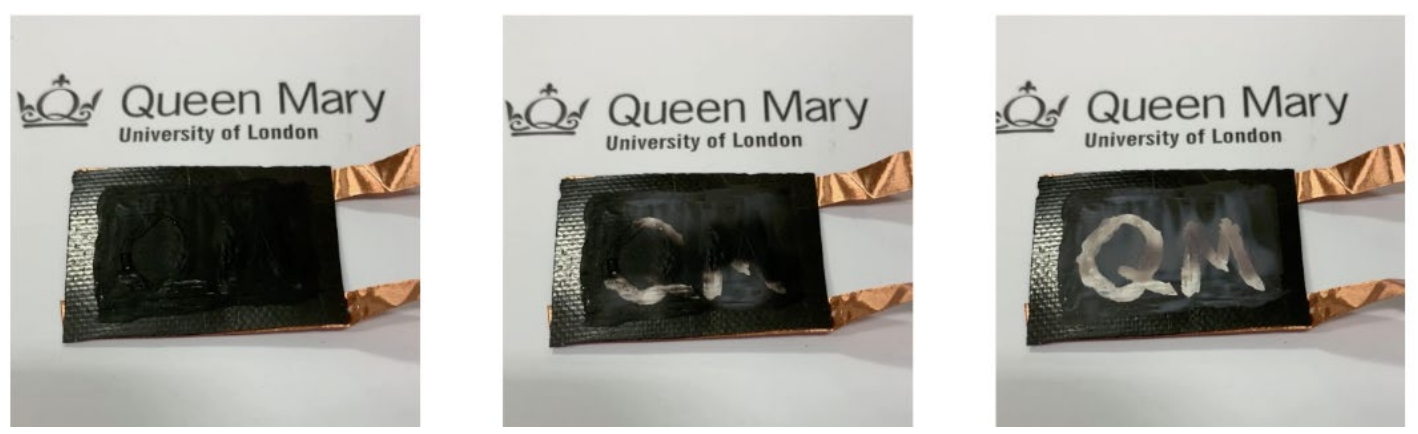

Figure 7 (a) Joule heating capability of cured GFRP laminate with embedded nanocomposite surface layer, from freezing environment $\left(-20^{\circ} \mathrm{C}\right)$ to $R T\left(20^{\circ} \mathrm{C}\right)$ within minutes; (b) thermal image of the composite laminate showing a homogeneous temperature distribution on the surface of the laminate. (c) colour change of thermochromic paint from black to transparent induced by Joule heating of the HDPE/GNP nanocomposite film, showing potential for colour changing and camouflage applications.

\subsection{Self-sensing capability of HDPE/GNP nanocomposite film}

The presence of an electrically conductive HDPE/GNP nanocomposite layer at the surface of an insulating GFRP laminate, allows for the possibility to detect external stimuli such as mechanical deformation using in-situ electrical sensing methods [5]. The self-sensing performance of the current smart composite system is examined and presented in Fig. 8, with the test set-up illustrated in Fig. 8a. The loading profile is defined by 10 triangular loading cycles (e.g. up to 
$0.2 \%$ strain to avoid early damage such as matrix cracking), separated by a relaxation period of one minute (Fig. 8b). The smart nanocomposite surface layer is positioned at the bottom (tensile) side of the laminate throughout the tests.

Fig. 8c shows the relative resistance change $\left(\Delta R / R_{0}\right)$ during cyclic loading to a strain of $0.1 \%$ and $0.2 \%$, both at a strain rate of $1 \% / \mathrm{min}$. For each cycle, the electrical sensing signal $(\Delta R / R 0)$ gradually increases with increasing strain during the loading process, reaching its highest point at peak strain before returning to its original value upon unloading. This is believed due to the tunnelling effect of electrons within the percolating network and the change in the distance between conductive fillers induced from external mechanical loading and deformation [41]. For what concerns the effect of strain amplitude on the self-sensing capability, the largest electrical resistance change was observed for the largest strain amplitudes, which is consistent with the mechanism of conductive network deformation based on percolated conductive networks [42]. Overall, a good correlation between strain and resistance change of the composite was observed, enabling the current electrical sensing method to be used to monitor structure deformation by correlating sensing signals to mechanical deformation of composite structures.

To examine the repeatability, stability and durability of the smart GFRP with embedded nanocomposite layer with respect to its potential for long-term health monitoring, cyclic loading experiments of 100 loading-unloading cycles with a strain of $0.1 \%$ and $0.2 \%$ strain were performed. The electrical resistance response over a total of 200 cycles is shown in Fig. 8d. It can be seen that the resistance response is stable, although a slightly decreasing trend of relative resistance change is observed. This observation is attributed to the reversible competition of the distance change between conductive particles during cyclic loading and the viscoelastic properties of matrix. With longer relaxation times between loading cycles, it is believed that this overall reducing trend will be minimised $[43,44]$. In general, the obtained sensing results show good repeatability and stability in terms of sensing performance using the embedded HDPE/GNP 
surface layer, confirming the great potential of the present nanocomposite pyroresistive film as an intelligent strain sensor for deformation monitoring of the GFRPs.

(a)

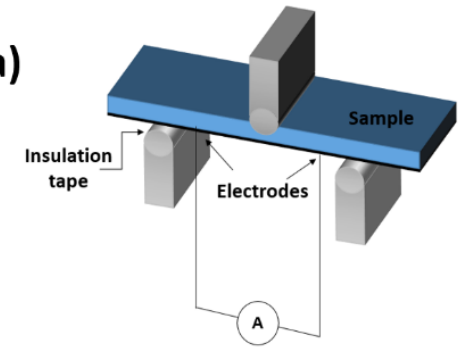

(b)

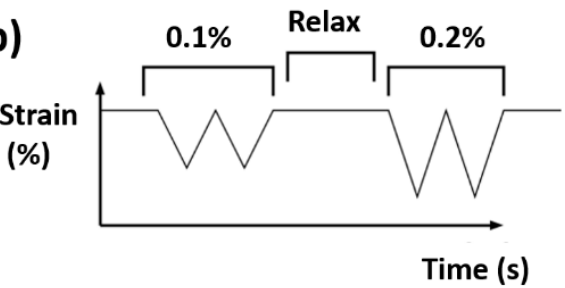

(c)

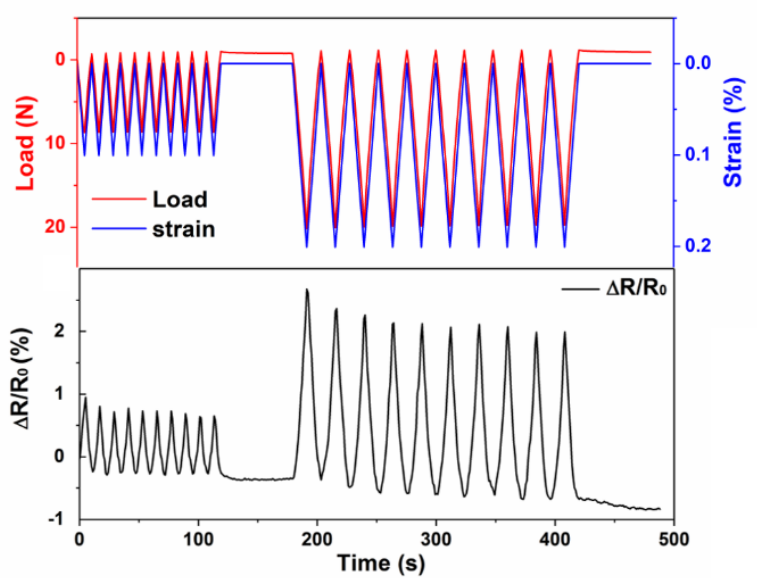

(d)
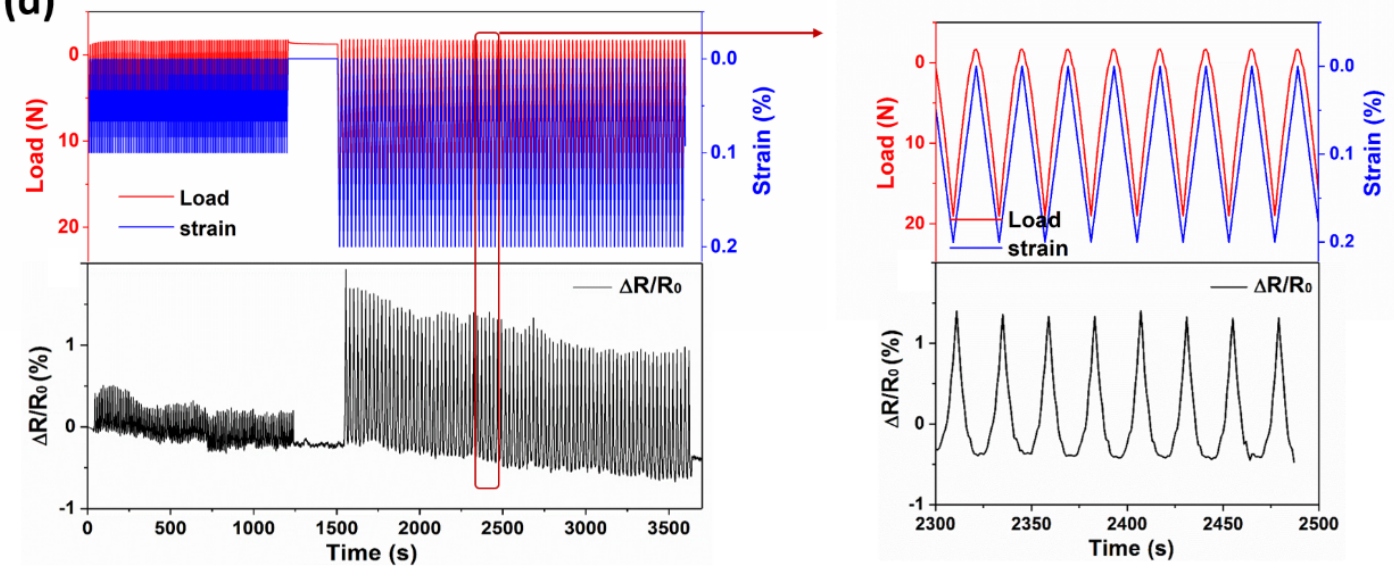

Figure 8 (a) Schematic illustration of three-point bending setup with in-situ electrical measurement; (b) schematic cyclic test profile; (c) electrical sensing data under cyclic loading at the strain of 0.1 and $0.2 \%$, showing excellent correlation between sensing signals and mechanical deformation; (d) cyclic loading at higher cycle numbers with good repeatability and stability of sensing signals.

Beyond the elastic deformation regime, the damage in the composite laminates can also be detected by the embedded HDPE/GNP smart surface layer. Fig. 9 shows a correlation between the electrical sensing signals and the applied load from the beginning of flexural testing until ultimate failure of the laminate. At the beginning of the test, a gradual increase in electrical 
resistance is observed with increasing loading level, which is consistent with previous findings from cyclic sensing tests at low strain levels. As the test continued, the sample showed a sudden jump in electrical resistance in correspondence with a clear drop in applied load, indicating obvious damage in the specimen. With each subsequent load drop as a result from continuing damage within the specimen, an obvious jump in electrical sensing signal can be observed. This good correlation between applied load and changes in electrical resistance, especially for the first load drop with an obvious resistance jump, implies that this methodology can be used as an integrated in-situ damage monitoring system for composites. However, it is worth noting that because the smart sensing layer is only present at the tensile surface of the laminates, early stage matrix cracking cannot be detected by the current sensing system.

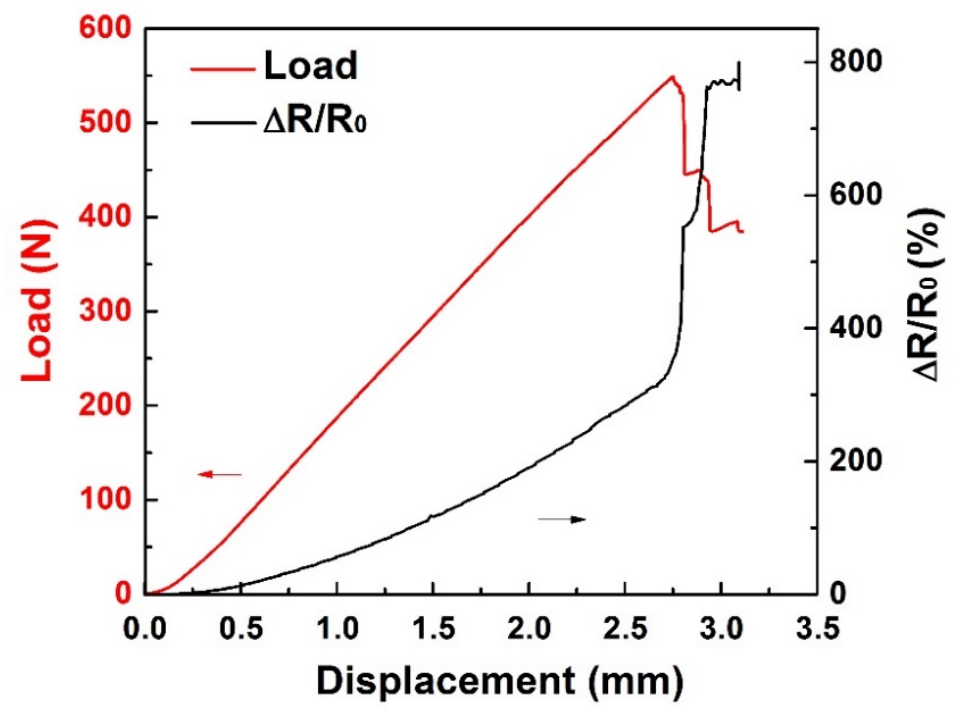

Figure 9 In-situ damage sensing of composite laminate with smart surface layer, showing a good correlation between electrical sensing signal and load response for both elastic deformation regime and damage of the composite at high strain level.

\section{Conclusions}


An extremely energy efficient and intrinsically safe method to manufacture thermoset based composites with integrated multifunctionalities has been developed. This sustainable and safe manufacturing method makes use of an integrated pyroresistive HDPE/GNP nanocomposite film with good self-regulating function and Joule heating capabilities. The nanocomposite film was embedded as a smart surface layer into a GFRP laminate to act as a self-regulating Joule heating source to perform safe out-of-oven curing with a very similar temperature profiles to oven heating, albeit at only $1 \%$ of electrical energy consumption. No obvious differences in $\mathrm{T}_{\mathrm{g}}$ and mechanical performance was found between the composite laminates cured by the Joule heating method and the traditional oven heating method, confirming the efficiency and potential of the self-regulating Joule heating method for curing epoxy based composites as an alternative to oven or autoclave heating methods.

After the successful curing of the GFRP laminates, the integrated smart nanocomposite heating film provides various multifunctionalities, including de-icing, colour changing, strain sensing and damage sensing capabilities, without affecting the original structural integrity. Efficient deicing performance was observed with a heating rate over $18{ }^{\circ} \mathrm{C} / \mathrm{min}$ from a sub-zero degrees Celsius environment to RT, with a homogeneous heat distribution throughout the laminate surface area. Excellent electrical strain sensing performance was also obtained with good cyclic repeatability and a clear correlation between electrical sensing signal and mechanical deformation to provide useful information for structural health monitoring (SHM) during the components' life.

In short, a promising route of utilising pyroresistive materials as a highly energy efficient and intrinsically safe curing method for thermoset composites has been demonstrated. The embedded multifunctional nanocomposite layer could serve from the energy efficient and safe manufacturing stage, throughout the usage of the final component as a heating or SHM system. The proposed technology is fully compatible with current composite manufacturing processes 
like VARTM or VARI, which could be easily utilised in various sectors like aerospace, civil and construction, as well as offshore wind energy with great potential to sustainably manufacture composites locally.

\section{Acknowledgements}

The authors gratefully acknowledge LMK Thermosafe Ltd. for support and fruitful discussions.

\section{Reference}

[1] E.T. Thostenson, Z. Ren, T.-W. Chou, Advances in the science and technology of carbon nanotubes and their composites: a review, Composites science and technology 61(13) (2001) 1899-1912. [2] L.-Y. Lin, J.-H. Lee, C.-E. Hong, G.-H. Yoo, S.G. Advani, Preparation and characterization of layered silicate/glass fiber/epoxy hybrid nanocomposites via vacuum-assisted resin transfer molding (VARTM), Composites Science and Technology 66(13) (2006) 2116-2125.

[3] K. Zhang, Y. Gu, Z. Zhang, Effect of rapid curing process on the properties of carbon fiber/epoxy composite fabricated using vacuum assisted resin infusion molding, Materials \& Design (1980-2015) 54 (2014) 624-631.

[4] L. Gao, E.T. Thostenson, Z. Zhang, T.W. Chou, Sensing of damage mechanisms in fiber - reinforced composites under cyclic loading using carbon nanotubes, Advanced functional materials 19(1) (2009) 123-130.

[5] H. Zhang, E. Bilotti, T. Peijs, The use of carbon nanotubes for damage sensing and structural health monitoring in laminated composites: a review, Nanocomposites 1(4) (2015) 167-184.

[6] T.-W. Chou, L. Gao, E.T. Thostenson, Z. Zhang, J.-H. Byun, An assessment of the science and technology of carbon nanotube-based fibers and composites, Composites Science and Technology 70(1) (2010) 1-19.

[7] Y. Liu, H. Zhang, H. Porwal, W. Tu, K. Wan, J. Evans, M. Newton, J.J.C. Busfield, T. Peijs, E. Bilotti, Tailored pyroresistive performance and flexibility by introducing a secondary thermoplastic elastomeric phase into graphene nanoplatelet (GNP) filled polymer composites for self-regulating heating devices, Journal of Materials Chemistry C 6(11) (2018) 2760-2768.

[8] P. Song, C. Liang, L. Wang, H. Qiu, H. Gu, J. Kong, J. Gu, Obviously improved electromagnetic interference shielding performances for epoxy composites via constructing honeycomb structural reduced graphene oxide, Composites Science and Technology 181 (2019) 107698.

[9] R. Schueler, S.P. Joshi, K. Schulte, Damage detection in CFRP by electrical conductivity mapping, Composites Science and Technology 61(6) (2001) 921-930.

[10] H. Zhang, Y. Liu, M. Kuwata, E. Bilotti, T. Peijs, Improved fracture toughness and integrated damage sensing capability by spray coated CNTs on carbon fibre prepreg, Compos. Pt. A-Appl. Sci. Manuf. 70 (2015) 102-110.

[11] C. Li, E.T. Thostenson, T.W. Chou, Sensors and actuators based on carbon nanotubes and their composites: A review, Composites Science and Technology 68(6) (2008) 1227-1249.

[12] F. Mai, Y. Habibi, J.-M. Raquez, P. Dubois, J.-F. Feller, T. Peijs, E. Bilotti, Poly(lactic acid)/carbon nanotube nanocomposites with integrated degradation sensing, Polymer 54(25) (2013) 6818-6823. 
[13] H. Zhang, M. Kuwata, E. Bilotti, T. Peijs, Integrated damage sensing in fibre-reinforced composites with extremely low carbon nanotube loadings, Journal of Nanomaterials 2015(Article ID 785834) (2015) 7.

[14] L. Vertuccio, F. De Santis, R. Pantani, K. Lafdi, L. Guadagno, Effective de-icing skin using graphenebased flexible heater, Composites Part B: Engineering 162 (2019) 600-610.

[15] J. Lee, I.Y. Stein, S.S. Kessler, B.L. Wardle, Aligned carbon nanotube film enables thermally induced state transformations in layered polymeric materials, ACS Appl Mater Interfaces 7(16) (2015) 8900-5.

[16] T. Xia, D. Zeng, Z. Li, R.J. Young, C. Vallés, I.A. Kinloch, Electrically conductive GNP/epoxy composites for out-of-autoclave thermoset curing through Joule heating, Composites Science and Technology 164 (2018) 304-312.

[17] B. Mas, J.P. Fernández-Blázquez, J. Duval, H. Bunyan, J.J. Vilatela, Thermoset curing through Joule heating of nanocarbons for composite manufacture, repair and soldering, Carbon 63 (2013) 523-529. [18] L. Qiu, P. Guo, X. Yang, Y. Ouyang, Y. Feng, X. Zhang, J. Zhao, X. Zhang, Q. Li, Electro curing of oriented bismaleimide between aligned carbon nanotubes for high mechanical and thermal performances, Carbon 145 (2019) 650-657.

[19] S.G. Prolongo, R. Moriche, G. Del Rosario, A. Jiménez-Suárez, M.G. Prolongo, A. Ureña, Joule effect self-heating of epoxy composites reinforced with graphitic nanofillers, Journal of Polymer Research 23(9) (2016) 189.

[20] J. Lee, X. Ni, F. Daso, X. Xiao, D. King, J.S. Gómez, T.B. Varela, S.S. Kessler, B.L. Wardle, Advanced carbon fiber composite out-of-autoclave laminate manufacture via nanostructured out-of-oven conductive curing, Composites Science and Technology 166 (2018) 150-159.

[21] X. Xu, Y. Zhang, J. Jiang, H. Wang, X. Zhao, Q. Li, W. Lu, In-situ curing of glass fiber reinforced polymer composites via resistive heating of carbon nanotube films, Composites Science and Technology 149 (2017) 20-27.

[22] L. Zhu, R. Pitchumani, Analysis of a process for curing composites by the use of embedded resistive heating elements, Composites Science and Technology 60(14) (2000) 2699-2712.

[23] D. Sui, Y. Huang, L. Huang, J. Liang, Y. Ma, Y. Chen, Flexible and transparent electrothermal film heaters based on graphene materials, Small 7(22) (2011) 3186-3192.

[24] H. Chu, Z. Zhang, Y. Liu, J. Leng, Self-heating fiber reinforced polymer composite using meso/macropore carbon nanotube paper and its application in deicing, Carbon 66 (2014) 154-163. [25] S. Prolongo, R. Moriche, G. Del Rosario, A. Jiménez-Suárez, M. Prolongo, A. Urena, Joule effect self-heating of epoxy composites reinforced with graphitic nanofillers, Journal of Polymer Research 23(9) (2016) 189.

[26] H. Deng, L. Lin, M. Ji, S. Zhang, M. Yang, Q. Fu, Progress on the morphological control of conductive network in conductive polymer composites and the use as electroactive multifunctional materials, Progress in Polymer Science 39(4) (2014) 627-655.

[27] Y. Liu, H. Zhang, H. Porwal, W. Tu, J. Evans, M. Newton, J.J.C. Busfield, T. Peijs, E. Bilotti, Universal Control on Pyroresistive Behavior of Flexible Self-Regulating Heating Devices, Advanced Functional Materials 27(39) (2017) 1702253.

[28] Y. Liu, H. Zhang, H. Porwal, J.J. Busfield, T. Peijs, E. Bilotti, Pyroresistivity in conductive polymer composites: a perspective on recent advances and new applications, Polymer International 68(3) (2019) 299-305.

[29] A. Rybak, G. Boiteux, F. Melis, G. Seytre, Conductive polymer composites based on metallic nanofiller as smart materials for current limiting devices, Composites Science and Technology 70(2) (2010) 410-416.

[30] H. Xu, Y. Wu, D. Yang, J. Wang, H. Xie, Study on theories and influence factors of PTC property in polymer based conductive composites, Rev. Adv. Mater. Sci 27 (2011) 173-183.

[31] J. Feng, C.-M. Chan, Double positive temperature coefficient effects of carbon black-filled polymer blends containing two semicrystalline polymers, Polymer 41(12) (2000) 4559-4565.

[32] H. Xu, Z. Dang, D. Shi, J. Bai, Remarkable selective localization of modified nanoscaled carbon black and positive temperature coefficient effect in binary-polymer matrix composites, Journal of Materials Chemistry 18(23) (2008) 2685-2690. 
[33] H. Deng, T. Skipa, R. Zhang, D. Lellinger, E. Bilotti, I. Alig, T. Peijs, Effect of melting and crystallization on the conductive network in conductive polymer composites, Polymer 50(15) (2009) 3747-3754.

[34] R.S.-J.J.M. Walker, Method of making heater cable, Raychem Corp, United States, 1972, p. US3861029A.

[35] L. Chen, J. Hou, Y. Chen, H. Wang, Y. Duan, J. Zhang, Synergistic effect of conductive carbon black and silica particles for improving the pyroresistive properties of high density polyethylene composites, Composites Part B: Engineering (2019) 107465.

[36] A. Kernin, K. Wan, Y. Liu, X. Shi, J. Kong, E. Bilotti, T. Peijs, H. Zhang, The effect of graphene network formation on the electrical, mechanical, and multifunctional properties of graphene/epoxy nanocomposites, Composites Science and Technology 169 (2019) 224-231.

[37] Y. Li, H. Zhang, Y. Liu, H. Wang, Z. Huang, T. Peijs, E. Bilotti, Synergistic effects of spray-coated hybrid carbon nanoparticles for enhanced electrical and thermal surface conductivity of CFRP laminates, Composites Part A: Applied Science and Manufacturing 105 (2018) 9-18.

[38] K. Matsushige, K. Kobayashi, N. Iwami, T. Horiuchi, E. Shitamori, M. Itoi, Nanoscopic analysis of the conduction mechanism in organic positive temperature coefficient composite materials, Thin Solid Films 273(1) (1996) 128-131.

[39] T. Clyne, D. Hull, An introduction to composite materials, Cambridge university press2019.

[40] B. Ramakrishnan, L. Zhu, R. Pitchumani, Curing of composites using internal resistive heating, Journal of manufacturing science and engineering 122(1) (2000) 124-131.

[41] R. Zhang, M. Baxendale, T. Peijs, Universal resistivity-strain dependence of carbon nanotube/polymer composites, Physical Review B 76(19) (2007) 195433.

[42] Y. Tao, Y. Liu, H. Zhang, C.A. Stevens, E. Bilotti, T. Peijs, J.J.C. Busfield, Smart cord-rubber composites with integrated sensing capabilities by localised carbon nanotubes using a simple swelling and infusion method, Composites Science and Technology 167 (2018) 24-31.

[43] E. Bilotti, R. Zhang, H. Deng, M. Baxendale, T.J.J.o.M.C. Peijs, Fabrication and property prediction of conductive and strain sensing TPU/CNT nanocomposite fibres, 20(42) (2010) 9449-9455.

[44] R. Zhang, H. Deng, R. Valenca, J. Jin, Q. Fu, E. Bilotti, T. Peijs, Strain sensing behaviour of elastomeric composite films containing carbon nanotubes under cyclic loading, Composites Science and Technology 74 (2013) 1-5. 